\title{
Runoff quantity response of three urban mountain parks-hilltop subtype in humid subtropical climate based on SWMM
}

\author{
Yuanyuan Li, Jialin Liu, and Jianlin Zhang* \\ School of horticulture and landscaped architecture, Southwest University, Chongqing 400715, China
}

\begin{abstract}
With the development of sustainable stormwater management, urban parks have the advantages and necessities in constructing low impact development system to reduce and reuse stormwater. This study aims to understand the hydrological processes in small scale mountain watersheds based on three typical hilltop parks in Chongqing, China. Sub-catchment areas were divided into paved square type (PST), vegetation cover type (VCT) and mixed cover type (MCT). Native stromwater models by SWMM were created under $25 \mathrm{~mm}, 50 \mathrm{~mm}, 4$ years and 20 years precipitation events to simulate the runoff quantity. The runoff quantity per unit area in different sub-catchments was provided as : PST $>$ MCT $>$ VCT. Runoff quantity affected by impervious surface percentage was the most significant compared to other parameters. Positive correlation between slop and runoff quantity was showed visibly when slop was above 42 degrees. Peak runoff could be affected by characteristic width of sub-catchment.
\end{abstract}

\section{Introduction}

Stormwater runoff is from total precipitation deducting interception by plants, infiltration, catchment storage and evaporation, and moves on surface with gravity to form into a confluence [1-2]. The characteristics of runoff quantity based on the hydrology and hydraulics describe the movement of surface runoff to understand the flow process and provide a basis for stormwater management strategies.

The main urban city of Chongqing is located in southwest of China $\left(29^{\circ} 33^{\prime} 30^{\prime \prime} \mathrm{N}, 106^{\circ} 34^{\prime} 0^{\prime \prime} \mathrm{E}\right)$ with a large area crisscrossed by rivers and mountains. It has a humid subtropical climate according to the Köppen-Geiger climate classification typically with average annual precipitation of $1108 \mathrm{~mm}$ (Shapingba weather station, 1981-2010) that mostly occurs from May to October. Due to the affects of climate change and terrain barrier, the frequency of rainstorm has increased in recent years with features of short-term, high intensity which formed large amount of stormwater runoff. The number of mountain parks with obvious mountainous terrain is more than $50 \%$ of the total number of urban parks. Under the background of the development of sponge city in Chongqing, mountain parks as important open space have topographic and permeable advantages to create low impact development (LID) system that could reduce and reuse stormwater within the park. The complex landforms of low-mountain and parallel valley resulted in several types of mountain parks with different features of runoff movement process. The hilltop parks with higher elevation compared to the surrounding urban areas are the most significant type of stormwater output, which have rapid convergence and limited capacity of runoff storage. Many large-scale squares were created on the flat terrain resulting in high impermeability of catchments and heavy burden of municipal drainage system in torrential rain event.

Most researches of mountain parks in Chongqing focused on planting and space design with a few involving runoff control by qualitative analysis [3-4]. More quantitative analyses need to be focused on this area. The experimental site and simulation by hydro-hydraulic models were the two most common methods in the area of stormwater quantitative analysis. Experimental method was used to study runoff from a specific type of catchment [5-6]. Simulation by hydro-hydraulic models was used for analyzing runoff from a combination watershed [7]. The continuously developing hydro-hydraulic models could provide an operational platform for understanding runoff characteristics on comprehensive catchments in urban mountain parks. The stormwater management model (SWMM) is an internationally mature hydro-hydraulic model and have been verified to be practical for stormwater quantity analysis in small watersheds of urban areas in China [8-9]. 


\section{Research method}

\subsection{Selection of the research objects}

Three typical hilltop parks with different scales, topographic features and slope distribution were selected as the research objects: 1) Beibei Park (7.20 hectares) with slope between $5^{\circ}-40^{\circ}$ consists of four small hilltops; 2) Eling Park (4.73 hectares) dominates by unilateral hillside with more gentle slope (within $10^{\circ}$ ) and a scarp (above $45^{\circ}$ ); 3) Hong'en Temple Park (26.25 hectares) located at the top of a mountain has been separated by a north-south ridgeline with slope below $23^{\circ}$.

\subsection{Division method, principle and classification of the sub-catchment areas}

The sub-catchment area is a basic unit for the cognition of hydrological processes. Division of sub-catchment is different based on research scale. Manual division, Tyson polygon method and DEM automatic division by GIS are the common methods to divide sub-catchment [10-11]. In this research, sub-catchment was determined to use manual division method based on construction layout and topographic conditions, since this method was more practical to be used in small watersheds with relatively simple components of ground surface and diverse landscape distribution.

The principle of dividing sub-catchment areas was provided as follows: 1) Each sub-catchment had only one confluence outlet located at the lowest elevation of the terrain; 2) The boundary of the sub-catchment was determined by the ridge line of the terrain, direction turning point of runoff, hiking trails and pipe network that disconnect runoff; 3) Each sub-catchment consisted of no more than two large impervious squares based on the principle of runoff source control [12].

The three parks were divided into 42 sub-catchments (Fig.1). These sub-catchments could be classified into three typical types according to the components of ground surface: 1) paved square type (PST) with the proportion of intensive distributed impervious cover over $75 \%$ and average slope less than $6 \% ; 2$ ) vegetated cover type (VCT) with the proportion of impervious cover (mostly hiking trails and small scale square less than $120 \mathrm{~m}^{2}$ ) no more than $20 \%$ and average slope between $3 \%-84 \%$, dominated by permeable vegetated surface; 3 ) mixed cover type (MCT) with the proportion of impervious cover no more than $75 \%$ and average slope between 14\%-109\%, dominated by a combination of non-intensive distributed impervious pavement, vegetated cover and ponds.

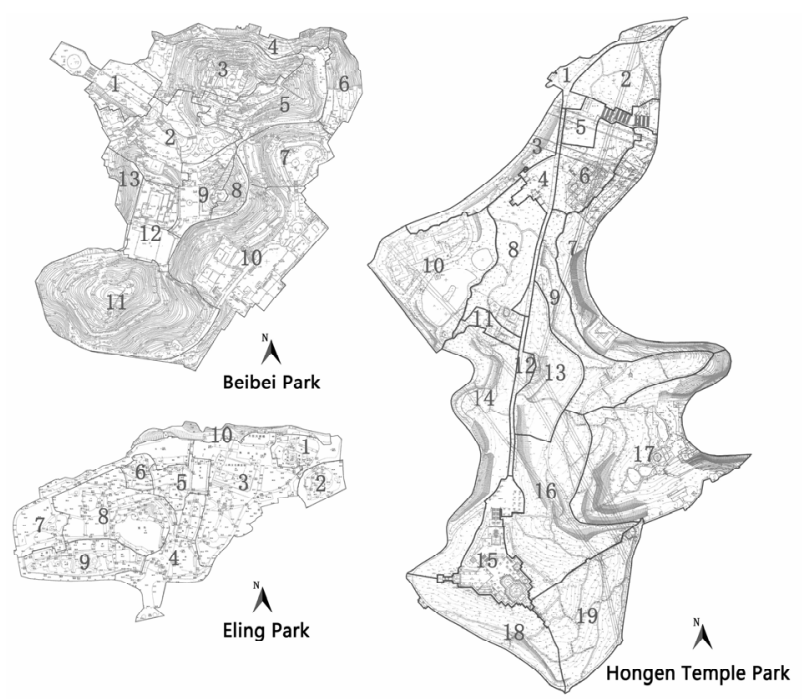

Fig. 1. The map of sub-catchment division.

\subsection{Model building}

\subsubsection{SWMM parameters setup}

1) Meteorological parameters

Four types of typical precipitation events $(25 \mathrm{~mm}, 50$ $\mathrm{mm}, 127 \mathrm{~mm}, 166 \mathrm{~mm}$ ) from the first two hours with five minutes recording interval were selected (Yubei weather station, Chongqing) (Fig.2). $127 \mathrm{~mm}$ and 166 $\mathrm{mm}$ were represented the typical precipitation events of 4 years and 20 years based on the average data of the top 8 precipitation events in recent 4 years and 8 years. The average evaporation from May to July was $5.07 \mathrm{~mm} / \mathrm{d}$ (Yubei weather station, Chongqing).

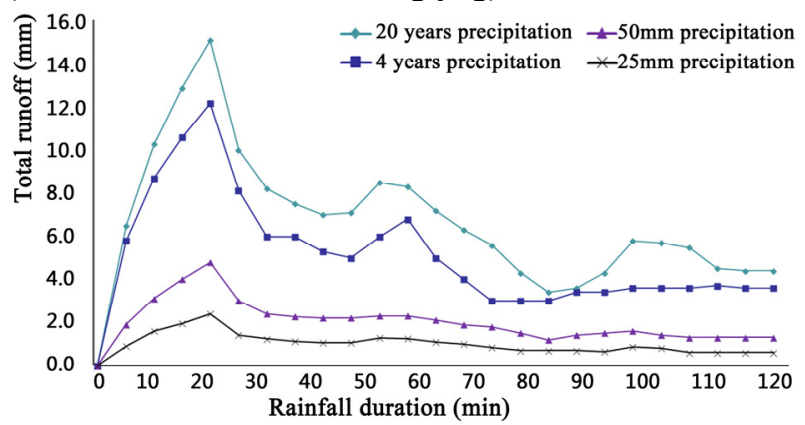

Fig. 2. Real-time rainfall runoff line chart.

2) Sub-catchment underlying surface parameters

The area of sub-catchments and the ratio of impervious surface were calculated based on topographic map. The characteristic width of sub-catchment was calculated by the equation: $\mathrm{W}=\mathrm{As} / \mathrm{L}$. As was represented the total area of sub-catchment. L was represented the length of the longest runoff path through the sub-catchment. The average slope was calculated by the equation: $S=\left(\sum S j \times A j\right) / A s . S j$ and $A j$ were represented the slope and area of each underlying surface, As was the total area of sub-catchment. Horton model was determined to use as infiltration model in this study. The attenuation coefficient was used recommended values provided by SWMM. Maximum infiltration rate of sub-catchment was calculated by the equation: $\mathrm{R}=\left(\sum \mathrm{Rp} \times \mathrm{Ap}\right) / \mathrm{Ag}$, $\mathrm{Rp}$ was represented the maximum 
infiltration rate of each typical planting type: lawn, shrubs plus lawn, trees plus lawn and the combination of lawn, shrubs, trees. Ap was represented the area of each typical planting type. Ag was represented the total area of vegetated cover. Saturated infiltration rate was calculated in a similar way. The maximum and saturated infiltration rates of each typical planting type in each park were tested in Lab based on soil samples in the field. Most tested saturated infiltration rates were higher than the recommended values provided by SWMM, since the surface soil in the field was affected by vegetation roots, gravel content and soil backfill during construction. In addition, Manning coefficient and depression storage of sub-catchment were used recommended values based on specific situation of underlying surface[13].

3) Pipe network parameters

The model parameters of pipe length, elevation and section were set combining with the park construction drawings and the actual layout of rainwater pipe network.

\subsubsection{Error assessment}

Simulation error is an important index to evaluate the operation effect of the model [14]. The continuity error of each simulation was used as verification according to the conservation of mass. The continuity errors of surface runoff and flow routing under four types of precipitation were less than $\pm 1.5 \%$. The simulation results fluctuated within a reasonable reference range.

\subsection{Data processing}

The parameters and simulation results of model were imported into SPSS software for correlation analysis.

\section{Result analysis}

\subsection{Surface runoff characteristics}

The total runoff per unit area, comprehensive runoff coefficient and peak runoff per unit area under four precipitation events in each sub-catchment area of the parks are shown in Figure 3. The runoff quantity between PST, MCT and VCT sub-catchments showed a decreasing trend. The VCT had a significant effect on total runoff reduction under $25 \mathrm{~mm}$ precipitation, and this reduction advantage decreased as precipitation intensity increasing (Fig.3 A). Comparing the variation of comprehensive runoff coefficient under four precipitation events, it could be found that variation rate of PST was less than $10 \%$, MCT was between $8 \%$ and $26 \%$, and VCT had the largest fluctuation (Fig.3 B). It indicated that the precipitation intensity had the least impact on PST sub-catchments, while had a significant impact on VCT. In addition, it could be seen that the effect of MCT on peak runoff reduction was significant (Fig.3 C). However, this reducing effect was greatly limited by steep slope (for example, EL-10, with the average slope above $45^{\circ}$, produced more than twice the peak runoff quantity compared to other VTC sub-catchments).
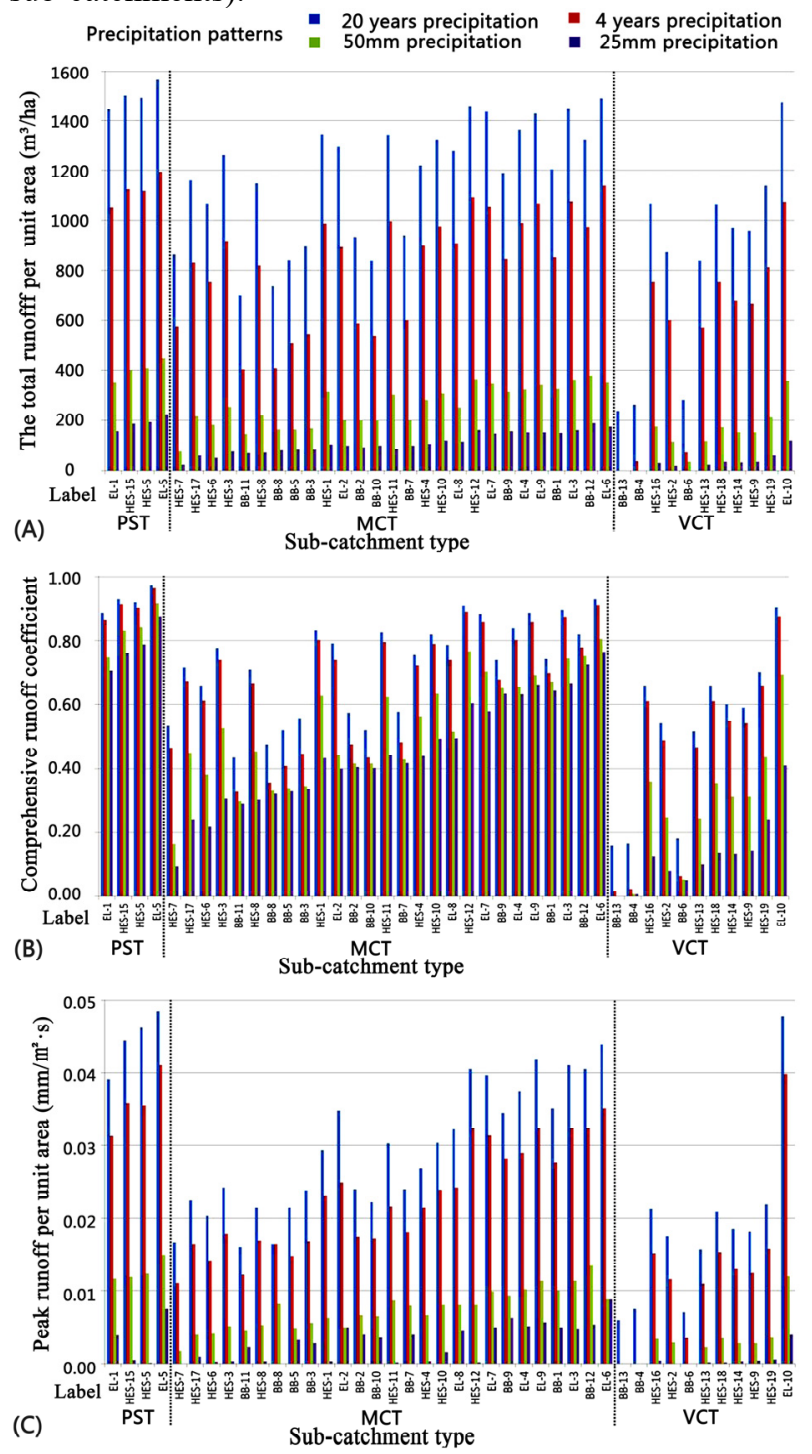

Fig. 3. Histogram of runoff characteristics in sub-catchment.

According to Figure 4, it was found that the runoff quantity of PST and MCT varied significantly with the real-time rainfall quantity under 4 years and 20 years precipitation events, forming a distinct flood peak between 20-30 minutes. The flood peak in VST sub-catchments was delayed to 60-70 minutes. 

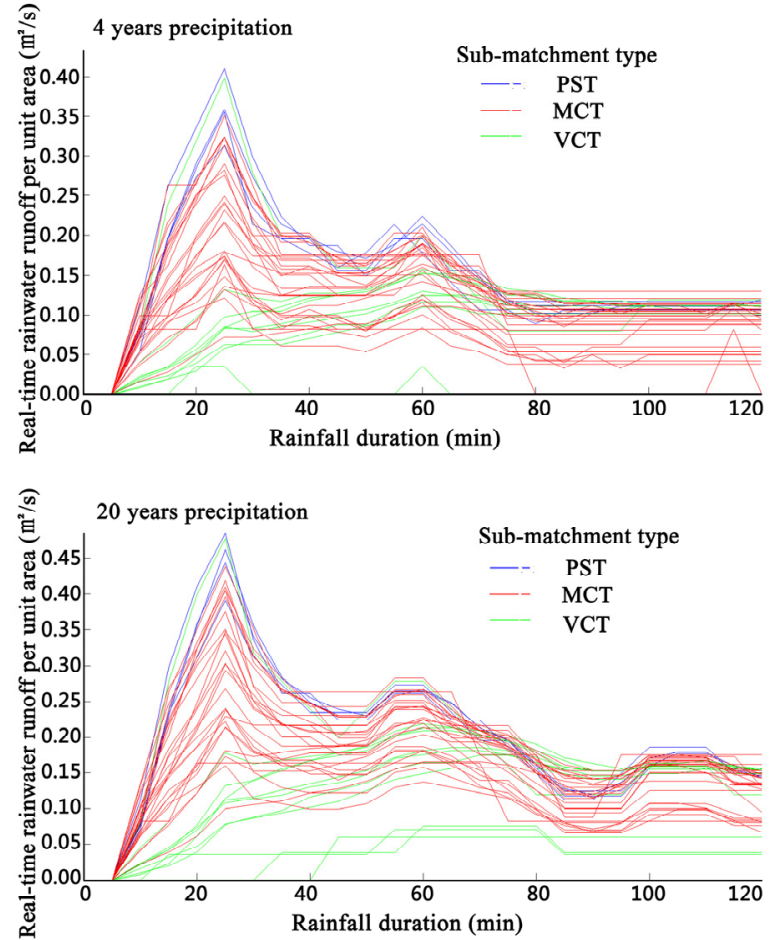

Fig. 4. Real-time runoff line chart of sub-catchment area under 4 years and 20 years precipitation.

Overland flow and pipeline flow are the main forms of surface runoff in mountain parks. Compared to pipeline transmission, runoff quantity could be reduced by slop transmission. The average reduction of three parks under $25 \mathrm{~mm}, 50 \mathrm{~mm}, 4$ years and 20 years precipitation were $17.59 \%, 13.36 \%, 8.71 \%$ and $7.35 \%$. In addition, three parks had overflow at some junction areas of downstream under torrential rain by simulating, which showed that the rainstorm bearing capacity of existing rainwater pipe network was insufficient.

\subsection{Analysis of influence factors}

\section{1) Impact of the imperviousness (Fig.5)}

There was a strong linear correlation under $25 \mathrm{~mm}$ and $50 \mathrm{~mm}$ precipitation events between total runoff per unit area and imperviousness (linear fit $\geq 0.78$ ), comprehensive runoff coefficient and imperviousness (linear fit $\geq 0.80$ ). Under $25 \mathrm{~mm}$ precipitation, the linear function $Y=208.945 X+10.749$ could be used to express the relationship between total runoff per unit area and imperviousness $\left(\mathrm{R}^{2}=0.953\right.$, sig. $\left.<0.05\right)$, and the linear function $\mathrm{Y}=0.854 \mathrm{X}+0.047$ could be used to express the relationship between comprehensive runoff coefficient and imperviousness $\left(\mathrm{R}^{2}=0.981\right.$, sig. $\left.<0.05\right)$. The effect of imperviousness on sub-catchment runoff was weakened with linear fit between 0.5-0.6 under 4 years and 20 years precipitation, which might indicate that other factors were highlighted under these conditions.
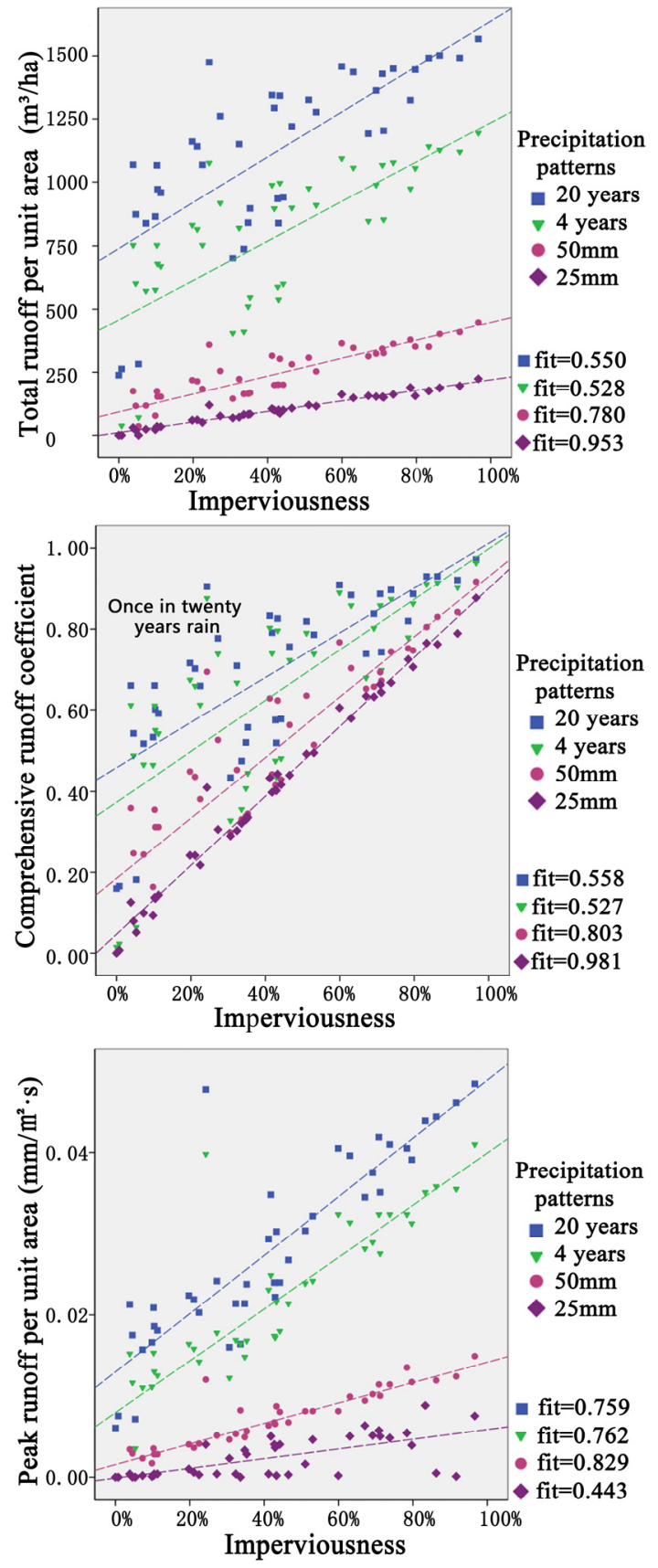

Fig. 5. Imperviousness correlation diagram.

The effect of imperviousness on the peak runoff per unit area was different from the above. The linear correlation (linear fit $=0.443$ ) between the two was the weakest under $25 \mathrm{~mm}$ precipitation. It might be deduced that there were other factors besides the imperviousness having significant impacts on peak runoff under small rainfall events with high frequency. The linear correlation (between 0.75-0.83) decreased with increasing precipitation intensity under the other three precipitation events, which showed that the improved effect of imperviousness on peak runoff reduction was gradually weakened following.

2) Impact of the average slope (Fig.6)

There was a quadratic function relationship between comprehensive runoff coefficient and average slope. Similar relationships were also existing between total runoff per unit area and average slope, peak runoff per unit area and average slope. Taking the comprehensive 
runoff coefficient as an example, the runoff coefficient decreased first and then increased with increasing average slope. However, the related research showed that the runoff coefficient increased with the increasing slope by the single variable control experiment [6]. When the average slope taken as a variable was less than $90 \%$ (about 42 degrees), the trend of the comprehensive runoff coefficient and the imperviousness were similar, and when the slope increased enough (more than 100\%), the homoplasy was broken. Thus, it could be deduced that in a certain range, the effect of average slope on runoff quantity was far less than imperviousness, and when the slope was steep enough, its positive correlation effect on surface runoff quantity was shown up.
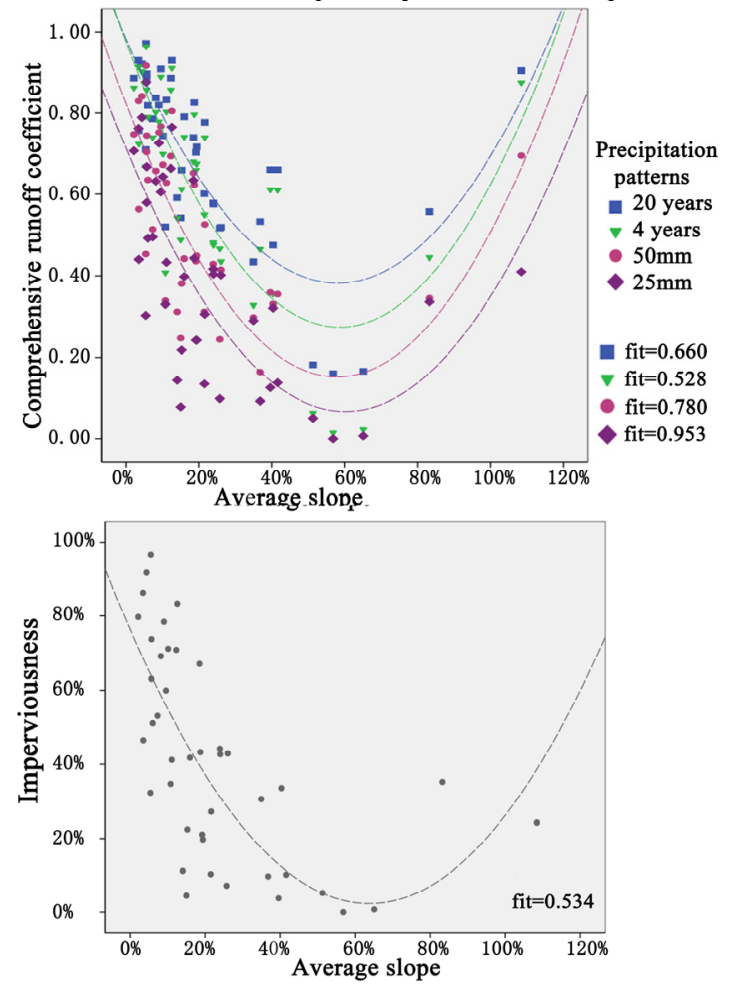

Fig. 6. Average slope correlation diagram.

3) Impact of the characteristic width (Fig.7)

The characteristic width could reflect length of runoff path from the opposite aspect. There was a certain positive linear correlation between total runoff peak and characteristic width. The linear fit increased with increasing precipitation intensity, which showed that the effect of characteristic width on the runoff peak was enhanced following.

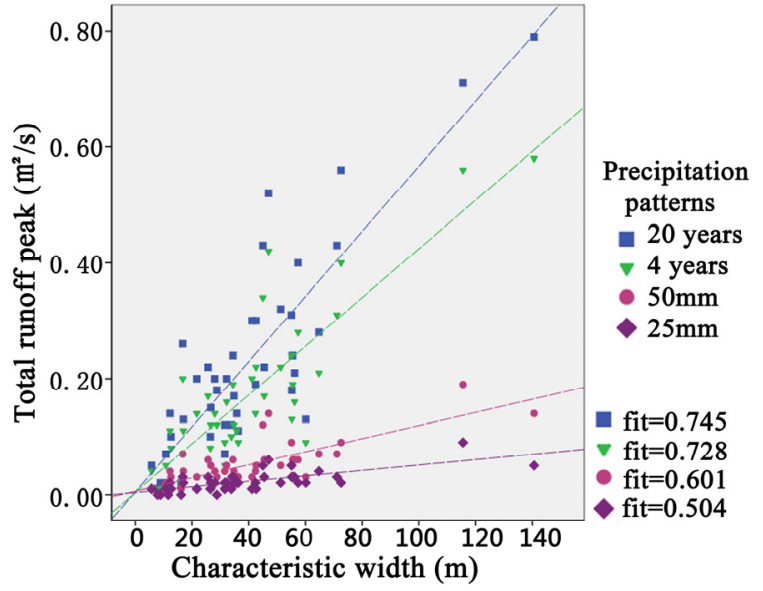

Fig. 7. Characteristic width correlation diagram.

\section{Conclusion}

This paper focused on hydrological processes in small scale mountain watersheds and revealed the relationship between impact factors and surface runoff, which could provide better understanding on runoff quantity and basic reference for sustainable stormwater management in mountain parks of Chongqing or similar mountain city in humid subtropical climate.

\section{Acknowledgement}

This research was financially supported by National Natural Science Foundation Youth Project (51708452) and Chongqing Basic Science and Frontier Technology Research Project (cstc2016jcyjA0391).

\section{References}

1. B.Z. Ren, S.J. Zhou, R.J. Deng, J. Nanhua Univ. (Nat. Sci.) 20(1), 8-12 (2006)

2. J. Liu, Y. He, Mount. Res. 36(1), 125-131 (2018)

3. J.L. Liu, J.L. Zhang, Landscape Architecture 3, 3544(2016)

4. Y.X. Lu, Park Landscape Design Based on the Perspective of Water Sensitivity. M.E. (Chongqing University, 2016)

5. M.X. Che, Y.B. Gong, M.N. Han, L. Liu, C. Lv, K.L. Kuang, Bull. Soil Water Conserv. 36(1), 125-131(2016)

6. Z.L. Hu, Study on runoff coefficient of mountain urban typical underlying surfaces. M.E. (Chongqing University, 2016)

7. L.H. Cai, Landscape Architecture 2, 33-43(2016)

8. X. Li, T.Y. Shi, G.J. Li, Water \&Wastewater Eng. 41(5), 152-156(2015)

9. W.X. Hu, W.H. He, G.R. Huang, J. Feng, Adv. water sci. 21(1), 137-144 (2010)

10. D.Q. Zhao, J.N. Chen, Q.Y. Tong, H.Z. Wang, S.B. Cao, Z. Sheng, Chin. Water \& Wastewater 24(7), 88-91(2008) 
11. L.S. Ma, L. Yao, H.P. Zhang, C.X. Hao, G.L. Yang,. Chin. Water \& Wastewater 27(15), 56-59(2011)

12. J.L. Liu, J.L. Zhang, Chinese Landscape Architecture 6, 81-87(2018)
13. L. Rossman, Storm Water Management Model (SWMM) User's Manual Version 5.0 (USEPA, 2010)

14. X.F. RUI, C.Y. JIANG, Q.J. CHEN, X.Y. Deng, $A d v$. Sci. Technol. Water Resour. 35(4) , 1-5(2015) 